\title{
ИСТОРИЧЕСКИЕ И ФИЛОСОФСКИЕ АСПЕКТЫ ВЗАИМОСВЯЗИ ПРЕДПРИНИМАТЕЛЬСКОЙ СРЕДЫ И ГОСУДАРСТВА
}

\begin{abstract}
АНнотАция. Представленная статья посвящена актуальным задачам изучения экономической, правовой и ментальной природы взаимодействия рыночных и государственных институтов, их оптимального сбалансированного сочетания. В частности, описываются исторические и философские аспекты взаимосвязи предпринимательской среды и государства на различных этапах эволюции таких отношений. Подробно обоснованы предпосылки, предопределяющие актуальность рассматриваемой проблемы, представлены результаты анализа ее теоретической разработанности, а также перечислены направления для обеспечения эффективности организации взаимодействия хозяйствующих субъектов и государственных институтов. Систематизированы и предложены ключевые понятия, раскрывающие специфичность взаимосвязи предпринимательской среды и государства. Проведен ретроспективный анализ основных предпосылок взаимосвязи государства и общества. Особое внимание уделено роли государства как регулятора экономической системы, имеющей объективные исторические и философские предпосылки, обуславливающие русло для формирования дальнейшей взаимосвязи предпринимательской среды и государственных институтов.

КЛЮчЕВЫЕ СЛОВА. ВЗаимодействие рыночных и государственных регуляторов; институциональная среда; эффективность государственного регулирования рыночной экономики.

ИНФОРМАЦИЯ О СТАТЬЕ. Дата поступления 1 февраля 2016 г.; дата принятия к печати 26 февраля 2016 г.; дата онлайн-размещения 31 марта 2016 г.
\end{abstract}

\section{V. Burovtsev \\ Siberian Railway Engineering University, Novosibirsk, Russian Federation}

\section{HISTORICAL AND PHILOSOPHICAL ASPECTS OF INTERRELATION OF BUSINESS ENVIRONMENT AND GOVERNMENT}

ABSTRACT. The article presented is devoted to topical tasks of studying economic, legal and mental nature of interaction of market and governmental institutions, their optimal balanced combination. In particular, it describes historical and philosophical aspects of interrelation of the business environment and the government at the various stages of the evolution of such relations. It substantiates in detail the prerequisites that predetermine the topicality of the problem at issue, presents the results of analyzing its theoretical development, as well as specifies the directions of providing the efficiency of maintaining interrelations between economic entities and governmental institutions. The article systemizes and offers the key concepts revealing the specificity of interaction of the business environment and the government, makes a retrospective analyses of the main prerequisites of interrelations between the government and the society. A special attention is paid to the government's role as a regulator of the economic system that has objective historical and philosophical prerequisites determining the mainstream for developing further interrelations of the business environment and the governmental institutions.

KEYWORDS. Interaction of market and governmental regulators; institutional environment; efficiency of governmental regulation of market economy.

ARTICLE INFO. Received February 1, 2016; accepted February 26, 2016; available online March 31, 2016.

\section{Baikal Research Journal}


Природа взаимосвязи общества и личности, государства и предпринимателя, их различные исторические и философские аспекты часто становились центром внимания исследователей на всех этапах цивилизационного развития.

Генезис понятий предпринимательства, предпринимательской среды и содержательной сущности государственного регулирования предпринимательской деятельности связан с историей естественного становления процессов обмена, производства и распределения товаров и услуг, с бурным развитием уровня производительных сил. Весьма лаконичное и вместе с тем достаточно емкое определение понятия предпринимательства дает В. И. Даль [1]. Так, указанным исследователем отмечается, что «предпринимать» означает «затевать, решаться исполнить какое-либо новое дело, приступать к совершению чего-либо значительного»: отсюда «предприниматель» - есть по сути «предпринявший» дело.

Вместе с тем в современной экономической литературе часто сущность предпринимательства как вида деятельности подменяется целью предпринимательской деятельности. К примеру, «Большой экономический словарь» под общей редакцией А. Н. Азрилияна приводит следующее определение: «Предпринимательство - инициативная самостоятельная деятельность граждан, направленная на получение прибыли или личного дохода, осуществляемая от своего имени, под свою имущественную ответственность или от имени и под юридическую ответственность юридического лица» [2]. В учебной литературе и на законодательном уровне понятие предпринимательства формулируется как самостоятельная и систематическая деятельность, осуществляемая на собственный риск, направленная на выполнение работ, оказание услуг с целью получения прибыли, которая осуществляется физическими и юридическими лицами, зарегистрированными, как субъекты предпринимательской деятельности в порядке, установленном законодательством. Гражданским кодексом Российской Федерации понятие предпринимательства формулируется как «самостоятельная, осуществляемая на свой риск деятельность, направленная на систематическое получение прибыли от пользования имуществом - продажи товаров, выполнения работ или оказания услуг, лицами, зарегистрированными в этом качестве в установленном законом порядке» ${ }^{1}$. Таким образом, общими характеризующими понятие «предпринимательская среда» как совокупности хозяйствующих субъектов должны быть значительный уровень риска при осуществлении хозяйственной деятельности, получение прибыли как стимул развития указанной деятельности, а также соответствующая государственная регистрация лиц, формирующих предпринимательскую среду [3].

Обращаясь к сути вопроса взаимосвязи государства и предпринимательской среды, необходимо признать, что образование, формируемое обширной территорией и проживающим на ней населением, осуществляющим хозяйственную деятельность, не может существовать и развиваться без соответствующих органов управления. Сущность государства - это, прежде всего, власть, ее принадлежность, назначение и функционирование в обществе. Иными словами, вопрос о сущности государства - это вопрос о том, кому принадлежит государственная власть, кто ее реализует и в чьих интересах. Понятие государства, содержащееся в Кратком политическом словаре, составленном Л. А. Ониковым и Н. В. Шишлиным, подчеркивает взаимосвязь роли государства и экономического устройства: «Сущность государства определяется характером производственных отношений, совокупность которых составляет экономический базис общества. Государство является политической надстройкой, но обладает относительной самостоятельностью, оказывая значительное

${ }^{1}$ Гражданский кодекс Российской Федерации (часть первая) : федер. закон от 30 нояб. 1994 г. № 51-Ф3 // СПС «КонсультантПлюс».

\section{Baikal Research Journal}

электронный научный журнал Байкальского государственного университета 
воздействие на все сферы общественных отношений, включая и экономику. Государство может способствовать развитию этих отношений или, напротив, тормозить их. История показывает, что по мере усложнения общества роль такого обратного воздействия государства на породивший его экономический строй возрастает» [4]. Реализация основных функций государства осуществляется посредством действий государственного аппарата - это та реальная организационная и материально воплощенная сила, располагая которой, государство осуществляет свою власть.

Как известно, исходный механизм взаимодействия человека (индивидуума) и окружающей его природной среды принял так называемую «натуральную форму хозяйствования», когда обмен и распределение результатов трудовой деятельности человека осуществлялся исходя из объема возникающих трудозатрат и ограничивался границами собственной общины или рода. В этих условиях отсутствовали такие современные экономические понятия, как прибавочная стоимость и цена, соответственно, экономические отношения носили простейшие, элементарные формы. Единственной формой взаимоотношений прообраза предпринимательской среды и государственных институтов стали простейшие виды налогообложения, например, такие как «иго» на содержание воинских подразделений «орды» или «дань» для содержания царствующей особы. В этих условиях фактически отсутствовали предпосылки к развитию инструментов государственного регулирования предпринимательской сферы. Следовательно, ввиду отсутствия соответствующих стимулов, механизмы воздействия государства на предпринимательскую среду в рассматриваемых условиях не получали какого-либо значимого развития.

В ходе цивилизационного развития произошло разделение производимого продукта на необходимый и прибавочный, исчезла сложившаяся связь между процессами обмена результатами трудовой деятельности и сложившимся естественным образом разделением труда. Возникшее в дальнейшем производство продукта в объеме, превышающем насущные потребности, стало основной предпосылкой для эволюционного перехода от естественного разделения труда к общественному. Общественное разделение труда обусловило возникновение понятия субъектов хозяйственной деятельности, соответствующих взаимоотношений между ними и государством. Указанный эволюционный переход от натурального хозяйства к товарному, сопровождаемый развитием производительных сил и инструментов государственного регулирования экономики, иллюстрирует собой исторический процесс становления системы взаимосвязи предпринимательской среды и государства.

Дальнейшее развитие экономических отношений между хозяйствующими субъектами позволило выделить элементы конкуренции, обусловить развитие соответствующих их видов и возможностей проявления предпосылок для монополизации. Естественным образом, диспропорции в развитии хозяйствующих субъектов, обусловленные стихийным характером механизмов саморегуляции рынка, предполагают возникновение противоречий в их действиях, в том числе в результате попыток монополизации отдельных рынков. В этих условиях закономерно возникает вопрос, какой субъект способен принять на себя ответственность по регулированию экономической системы. Учитывая стихийный характер рыночных отношений, такой регулятор должен быть принят всеми участниками рынка и удовлетворять их условиям. Оптимальное решение указанной задачи нашло отражение в процессе делегирования ряда полномочий участников рынка государственным институтам, наделенным соответствующим инструментарием, обеспечивающим целенаправленное воздействие на экономическую систему и не допускающим ее коллапса в виду периодически проявляющихся диспропорций развития экономики.

Подобная ситуация, когда государство наделяется функциями макроэкономического регулятора, имеет целый ряд естественных предпосылок: монопольные

\section{Baikal Research Journal}

электронный научный журнал Байкальского государственного университета 
участники рынка освобождаются от решений социальных вопросов, возникающих в результате структурных диспропорций экономики; конкурирующие участники рынка получают своего рода протекцию со стороны государства в отношении монополистов; конечный потребитель заинтересован в справедливых экономических отношениях, обеспечивающих конкурентные условия деятельности производителей, а соответственно, соревновательные элементы в отношении цены и качества потребляемых товаров и услуг. Таким образом, роль государства как регулятора экономической системы имеет объективные исторические предпосылки, обуславливающие русло для формирования дальнейшей взаимосвязи предпринимательской среды и государственных институтов.

Вместе с тем, важнейшее значение для понимания природы взаимосвязи общественных (государственных) и индивидуальных интересов имеет социально-философский генезис отношений государства и предпринимательской среды. Вопросы взаимоотношений государства, граждан, осуществляющих хозяйственную деятельность и формирующих предпринимательскую среду, составляли сферу интересов великих мыслителей далекого прошлого. Философские суждения о различных экономических аспектах взаимосвязи интересов населения и административных образований Древнего Египта, Передней Азии, Древнего Ирана, Древнего Китая, Древней Индии и Древней Греции сформировали основу большинства современных теоретических концепций развития государственного регулирования предпринимательской деятельности. Это обстоятельство обусловлено периодом зарождения государственности, осознанием отношений государства и граждан, идей совместного цивилизационного развития административных институтов и хозяйствующих субъектов.

В частности, особый интерес представляют дошедшие до нас из глубины веков труды древнегреческого философа Аристотеля (384-322 гг. до н. э.) [5]. В соответствии со взглядами Аристотеля, индивидуум живет для удовлетворения не только исключительно собственных потребностей, так как по своей природе человек является существом социальным, то он создан и для общественной жизни. Его связующими механизмами, обуславливающими взаимосвязь с обществом, являются кровные связи, единый язык, воспитанные с рождением нравственные инстинкты и др. При этом индивидуум испытывает потребность в общественном устройстве для наиболее эффективной собственной защиты, удовлетворения собственных первичных потребностей, а также своих социальных инстинктов, естественно присущих в разной степени любому индивидууму.

В соответствии с воззрениями древнегреческого философа, индивидуум не просто готов, а он испытывает обусловленную человеческой природой острую потребность в общении с подобными себе людьми не только в целях самореализации, реализации принципов соревновательности, но и осознавая необходимость в упорядочении собственной жизни «правом и законом» общества (государства). В понимании Аристотеля, «государство - есть совокупность граждан, достаточная для самодовлеющего существования" [6]. Указанное суждение свидетельствует об отношении государства (общества) к индивидууму как отношение целого к частному.

В понимании Аристотеля, совершенное общество, включающее в себя все целесообразные формы общественных и личностных взаимосвязей, есть государство «полис». Целью такого совершенного государственного устройства не является исключительно экономическая целесообразность. Согласно учению древнегреческого философа, государство не есть экономическая категория или объединение граждан, зиждущееся на исключительно материальных основах или индивидуальных, частных потребностях. Цель государства по Аристотелю - есть высшее всеобщее благо, состоящее из счастья индивидуумов. Отсюда и цель государственных институтов

\section{Baikal Research Journal}

электронный научный журнал Байкальского государственного университета 
определяется не как силовой или репрессивный аппарат, а как средство к формированию общественных благ путем развития блага каждого индивидуума, формирующего такое общество. Важнейшей функцией государства Аристотель видит «воспитательную» или идеологическую составляющую общественного устройства. В таком случае государство стоит выше таких институтов, как семья, экономические интересы узкой группы лиц. По своей природе государство водружается на первостепенное место как наиболее приоритетный институт в общественной иерархии.

Интересным представляется определенное противопоставление взглядов Аристотеля системе ценностей его учителя, древнегреческого философа Платона (428-347 гг. до н. э.), являвшегося, в свою очередь учеником великого Сократа (469-399 гг. до н. э.). Платон выступал с комплексной программой трансформации социально-экономических порядков взаимодействия государства и предпринимательской среды. Видное место в мировой истории экономической мысли занимают его исследования экономических проблем, изложенные в сочинениях «Государство» и «Законы». В частности, особого внимания заслуживает суждение Платона о запрете частной собственности и исключительной форме общественного владения, государственном регулировании различных сфер предпринимательской деятельности. Так, государство по Платону составлено тремя сословными частями [7]:

1. Высшее сословие, формируемое из числа воспитателей-философов, так как только люди, достигшие определенной степени просвещения, способны обеспечить верный образ жизни рядовых индивидуумов.

2. Сословие воинов - их первостепенная задача состоит в обеспечении безопасности государства, предотвращении всевозможных угроз как внутреннего, так и в особенности внешнего характера.

3. Сословие ремесленников, дельцов и крестьян - основная задача состоит в снабжении общества всем необходимым для его безбедного существования, иначе говоря, это «сословие кормильцев», инициативная предпринимательская среда того времени.

Важнейшим аспектом целостной системы взглядов взаимосвязи государства и предпринимательской среды по Платону является общественная форма владения имуществом различного рода, при этом частная собственность им просто запрещается. Более того, женщины и дети являются достоянием общества, а демографические показатели, по мнению указанного древнегреческого философа, должны регулироваться государством с целью выбора лучших.

Важнейшее значение в понимании взаимосвязи государства и предпринимательской среды характеризует понятие труда, который согласно постулатам учения Платона распределяется государством по способностям индивидуума и в интересах общества. Указанные положения имеют чрезвычайно важное значение в понимании предпосылок взаимосвязи государства и предпринимательской среды. Фактически, изложенный подход является прообразом, характеризующим роль государства как макроэкономического института регулирования экономики. Развитие подобной системы взглядов предполагает формирование достаточных механизмов макроэкономического планирования и прогнозирования, оценки способностей индивидуума, составляющего тот или иной сословный класс.

Экстраполируя предпосылки, изложенные Платоном более 2 тыс. лет назад, на современное понимание роли государства, возможно объяснить наличие таких институтов, как, например, лицензирование или сертификация. Институт лицензирования предпринимательской деятельности обуславливается пониманием тоталитарной роли государства, лучше других понимающего, какой вид деятельности способен выполнить тот или иной субъект предпринимательской деятельности, при

\section{Baikal Research Journal}


этом мандат на выполнение указанной деятельности государство получает от имени самих же индивидуумов, составляющих само общество.

Государственное устройство Платона во многом обосновывает применение самых жестких мер государственного регулирования экономики и сегодня. По сути, указанное философское учение является идеологической основой административно-командных и государственно-монополистических подходов в развитии современной экономки.

Напротив, по политическому учению Аристотеля, только индивидуум есть неделимая единица, а государство по своей структуре многочленное. При этом оно не просто составлено из множества членов, но более того они различные по своим качественным характеристикам. Аристотель считал, что государство перестало бы быть таковым, если бы оно приняло утопичные монолитные свойства государственного устройства Платона.

Указанный постулат подтверждает целесообразность и жизнеспособность гармоничного сочетания различных экономических и административных формаций, а также обосновывает принципы многоукладности взаимосвязи государственного устройства. В обоснование такой идеи Аристотель обращает внимание на то, что в своем понимании коммунистического устройства взаимоотношений государства и предпринимательской среды Платон игнорирует целый ряд институциональных факторов, существование имущественных и экономических связей, на которых фактически базируется жизнеспособная модель общественного устройства. Общественные противоречия вовсе не нивелируются при образовании утопичного, по мнению Аристотеля, государства-коммуны, более того, они в большем масштабе проявятся в условиях общественных форм собственности.

Древнегреческий философ Аристотель настаивает на том, что эгоизм естественен, он является своеобразным стимулом развития, в том числе предпринимательской инициативы. Естественные семейные ценности, экономические интересы клана, узкой общины - это есть первооснова, элементарная часть, «кирпичик», составляющий монолит общественного блага. Согласно Аристотелю индивидуум естественным образом призван более заботиться о собственных интересах, нежели блюсти общественный интерес, а следовательно, нивелируя институт семьи, различные формы собственности, государственный коммунизм определяет мощнейшие стимулы общественного развития.

Широко известный немецкий философ, социолог, экономист, писатель, поэт, политический и общественный деятель К. Маркс считал Аристотеля «экономистом-теоретиком» рабовладельческого строя [8]. Однако именно Аристотель был одним из первых исследователей древности, обратившим свое внимание на процессы обмена и пытавшимся постичь закономерности товарной экономики во взаимодействии с государственными институтами.

Завершение процесса развития рабовладельческого строя в Древнем Риме ознаменовало окончание эпохи расцвета философских воззрений на взаимоотношения предпринимательской среды и государственных институтов, с этого момента научная мысль получила прагматичный социально-экономический вектор своего развития. Исторические и философские предпосылки взаимосвязи государственных институтов и предпринимательской среды нашли свое отражение во взаимодействии, принявшем на современном этапе форму процесса оказания (потребления) государственных услуг.

Таким образом, целесообразно сделать следующее заключение: основополагающие теоретические подходы, изложенные более 2 тыс. лет назад способны во многом объяснить современные аспекты взаимоотношений государства и предпринимательской среды.

\section{Baikal Research Journal}


Касаясь исторической основы развития отечественных государственных институтов, обеспечивающих взаимосвязь с предпринимательской средой, необходимо провести определенный экскурс в прошлое нашей государственности. Значительный вклад в развитие указанных вопросов сделан отечественным ученым, кандидатом исторических наук В. А. Рогозой. Приведенный исторический экскурс выполнен на основе анализа научных материалов и открытых интернет-публикаций указанного автора и собственных исследованиях $[3 ; 9 ; 10]$.

Период активного формирования отечественной системы взаимодействия государственных институтов и предпринимательской среды начался с объединением русских княжеств вокруг г. Москвы и утверждением самодержавной власти великого князя. В этот период на Руси начала создаваться система государственного управления, важное место в которой заняли приказы, ставшие прообразами последующих министерств. Приказам предшествовали два общегосударственных органа, существовавших в XV в. при великом князе, - Дворец (дворцовое ведомство) и Казна. Кроме того, сложилась система, когда великий князь поручал (приказывал) кому-то из бояр или окольничих выполнять определенный круг обязанностей, связанный с обеспечением функционирования различных сторон жизни государства. Естественно, что у таких исполнителей разовых или постоянных поручений появлялись помощники, а то и целый штат людей, которые объединялись в постоянно действующий «путь», повытье или «избу». Постепенно утвердилось и название этого своеобразного административного органа - приказ.

Приказная система создавалась постепенно, путем приобретения все большей автономии от дворцового ведомства и Казны, специализации их отдельных государственно-управленческих функций, а также передачей новым административным образованьям части функций, бывших прерогативой великого князя и его ближайшего окружения, в том числе судебных, финансовых, военных, дипломатических и т. д. Первое дошедшее до нас упоминание о приказах относится к 1512 г., когда в документе зафиксирован термин «Казенный приказ».

Четкой классификации приказов в те времена не существовало, но условно их можно разделить на функциональные (ведомственные) и территориальные, дворцовые и общегосударственные. Особенностью российских приказов было то, что они объединяли судебную и административную власть, а также значительно дублировали функции друг друга. Первоначально приказами управляли бояре, но затем руководителями небольших приказов стали назначать и дьяков. Поскольку количество приказов стремительно увеличивалось, дьяки стали назначаться и на государственнозначимые приказы, получая при этом чин думных дьяков. Некоторые бояре и дьяки могли одновременно возглавлять несколько приказов. Например, в начале XVIII в. думный дьяк Виниус руководил сразу тремя приказами.

Даже по сроку своей непосредственной активной деятельности приказы существенно различались. Одни существовали всего несколько лет, другие развивались целыми столетиями. Такими «долгожителями» были дворцовые и военные приказы, а также Посольский и Поместный. Количество одновременно функционировавших приказов в России порой доходило до 80. Приказная система была очень громоздкой, неповоротливой и сложной в управлении. Коренные преобразования приказной системы начал Петр I, заменивший основные приказы коллегиями, но последний приказ, Сибирский, был ликвидирован только при Екатерине II в 1763 г.

На данном этапе развития отечественной системы государственного регулирования выделение государственного сектора сферы услуг, как самостоятельного сегмента или направления, достаточно затруднительно. Указанное обстоятельство в первую очередь обусловлено концептуально иным пониманием роли и задач государственных институтов. Впоследствии эта роль значительно эволюционировала в

\section{Baikal Research Journal}

электронный научный журнал Байкальского государственного университета 
ходе развития общественных отношений, что в корне изменило характер взаимоотношений государственных институтов и пользователей государственных услуг. Эволюция в понимании подходов к организации взаимоотношений между государством и предпринимательской средой стала предпосылкой к открытию новых возможностей в оценке эффективности государственных услуг, формированию новых механизмов управления государственным сектором сферы услуг.

В этой связи интересно проследить историческую и функциональную трансформацию вертикали органов государственной власти применительно к отдельной отрасли, например, в отношении отрасли железнодорожного транспорта. В самом недалеком прошлом именно эта вертикаль власти перешагнула свой двухвековой рубеж развития.

Первые упоминания об органах государственного управления, связанных с перевозками, относятся к середине XVI в. - Ямской приказ, который просуществовал до 1711 г. На его основе образован впоследствии Почтовый департамент (1782). В 1733 г. создана Канцелярия перспективной дороги Москва -Петербург, которая в 1755 г. стала называться Канцелярией строения государственных дорог. Отсюда берет начало орган государственного управления дорожной отраслью. В 1798 г. образован Департамент водяных коммуникаций, что является датой рождения органа государственного управления на речном транспорте. 20 ноября 1809 г. вышел Манифест императора Александра I, которым учреждено Управление водяными и сухопутными сообщениями и Институт корпуса инженеров путей сообщения. При главном директоре этого управления учреждается Экспедиция, подразделяющаяся на три разряда: водяных сообщений, сухопутных сообщений и торговых портов. Создан Совет Управления. Для лучшего управления водяными и сухопутными сообщениями пространство Российской империи разделяется на 10 округов.

Дата учреждения Управления водяными и сухопутными сообщениями является датой рождения единого органа государственного управления всеми видами тогда имевшегося транспорта: речного, морского и дорожного хозяйства, а также создания надзора и территориальных органов управления путями сообщения.

1809 г. считается также годом рождения российской транспортной науки и образования. При Управлении водяными и сухопутными сообщениями «для образования способных исполнителей учреждается особый институт» - Институт для Корпуса Инженеров в С. Петербурге. «Инспектором предполагаемого института для образования юношества в науках, нужных по части водяных сообщений» назначается генерал-лейтенант А. Бетанкур, а в 1810 г. осуществлен первый прием воспитанников.

Управление водяными и сухопутными коммуникациями преобразовано в Главное управление водяными и сухопутными коммуникациями. Своим Именным указом от 25 августа 1814 г. Александр I повелевает, чтобы «правящий ныне должность Главного Директора путей сообщения Инженер-Генерал Деволант присутствовал по своей части в Комитете Министров, и адресовался в оный на правах прочих Министров», так как «при разделении Государственных дел, Главное Управление путей сообщения осталось в порядке, определенном учреждением 20 ноября 1809 г., и составляет собой отдельное Министерство» .

В 1833 г. Главное управление водяными и сухопутными коммуникациями преобразовано в Главное управление путей сообщения и публичных зданий. В 1842 г. в его составе образован Департамент железных дорог. В 1864 г. Институт Корпуса инженеров путей сообщения преобразован в Институт инженеров путей сообщения. В 1865 г. Главное управление путей сообщения и публичных зданий преобразовано в Министерство путей сообщения. Министерство состояло из 4 департаментов: сухопутных сообщений, водяных сообщений, железных дорог, ревизий и отчетов.

\section{Baikal Research Journal}


В таком виде Министерство путей сообщения просуществовало до 1918 г., а потом было преобразовано в Народный комиссариат путей сообщения. В 1930 г. Институт инженеров путей сообщения преобразован в два самостоятельных учебных заведения: Ленинградский институт инженеров водного транспорта, образованный на базе водного факультета, и Ленинградский институт инженеров железнодорожного транспорта, образованный на базе строительного, механического и эксплуатационного факультетов. В 1931 г. Народный комиссариат путей сообщения, как единый орган управления на транспорте, прекратил существование и разделился на комиссариаты по отдельным видам транспорта.

В 1990 г. создано Министерство транспорта РСФСР, которое задумывалось как единый орган государственного управления на транспорте и объединило под своим началом дорожное хозяйство, автомобильный, речной, морской, промышленный транспорт и гражданскую авиацию. В 1991 г. создано Министерство транспорта РФ. В 1992 г. на базе упраздненного Министерства путей сообщения СССР создано Министерство путей сообщения РФ, как федеральный орган исполнительной власти на железнодорожном транспорте.

Указом Президента РФ «О системе и структуре федеральных органов исполнительной власти» от 9 марта 2004 г. № 314 Министерство транспорта РФ и Министерство путей сообщения РФ упразднены. Одновременно образовано Министерство транспорта и связи РФ, а 20 мая 2004 г. Минтранссвязи России преобразовано в Министерство транспорта РФ и Мининформсвязи России (указ Президента Российской Федерации от 20 мая 2004 г. № 649). Таким образом, 20 мая 2004 г. в России был воссоздан единый федеральный орган исполнительной власти в области транспорта. Идея реализации единых комплексных подходов в формировании институциональных основ государственного регулирования, обеспечивающих гармоничное и согласованное развитие всех видов транспорта, доказала свою историческую жизнеспособность.

Итак, в процессе становления современной цивилизации были сформированы ключевые исторические и философские предпосылки развития двух тесно взаимозависимых институциональных образований - государственной и предпринимательской среды. Изначально возникая ввиду проявления разнонаправленных стимулов, указанные институты были обречены тесно взаимодействовать в процессе решения смежных задач своей деятельности, по сути, составляющих единую целостную приоритетную цель - эффективное достижение общественного блага. Однако в процессе эволюционного развития степень взаимной зависимости государственных и рыночных институциональных образований неуклонно росла и определялась возможностями эффективной организации взаимодействия между ними. По этой причине и уровень развития общественных отношений во многом соотносится с возможностями гармоничного сочетания усилий государства и рыночных механизмов саморегуляции, многоукладности экономических формаций. Указанное обстоятельство подтверждается результатами целого ряда отечественных научных исследователей [11-14].

Вместе с тем и на современном этапе эволюционного развития указанные институциональные образования продолжают обладать достаточными признаками обособленности, изначально обусловленными первопричинами возникновения понятий предпринимательской среды и государства. Современным эволюционным этапом указанных взаимоотношений государства и бизнеса стала широко развитая система государственных услуг.

\section{Список использованной литературы}

1. Даль В. И. Толковый словарь живого великорусского языка : в 4 т. / В. И. Даль. - М. : ГИС, 1955.

\section{Baikal Research Journal}


2. Большой экономический словарь / под ред. А. Н. Азрилияна. - М. : Фонд «Правовая культура», 1994. - 528 с.

3. Буровцев В. В. Экономическая оценка лицензионного барьера при формировании конкурентной среды на рынке грузовых железнодорожных перевозок : дис. ... канд. экон. наук : 08.00.05 / В. В. Буровцев. - Новосибирск, 2006. - 190 с.

4. Чанышев А. Н. Курс лекций по древней философии / А. Н. Чанышев. - М. : Высш. шк., 1981. - $374 \mathrm{c}$.

5. Аристотель. Сочинения : в 4 т. / Аристотель ; под ред. В. Ф. Асмуса. - М. : Мысль, 1975-1983. - (Сер. «Философское наследие»).

6. Душенко К. В. Универсальный цитатник политика и журналиста: 6000 цитат о политике, правосудии и журналистике / К. В. Душенко. - 4-е изд., испр. - М. : Эксмо, 2006. - 508 с.

7. Краткий политический словарь / сост. и ред. Л. А. Оникова, Н. В. Шишлина. 5-е изд., доп. - М. : Политиздат, 1989. - 623 с.

8. Всемирная история экономической мысли : в 6 т. / под ред. В. Черковца. - М. : Мысль, 1987. - T. 1. - $606 \mathrm{c.}$

9. Буровцев В. В. Управление административным барьером в условиях трансформации экономической системы: монография / В. В. Буровцев. - Новосибирск : Изд-во Сиб. гос. унта путей сообщения, 2011. - 159 с.

10. Буровцев В. В. Государственное регулирование железнодорожного транспорта в период реформирования : учеб. пособие / В. В. Буровцев, И. В. Мицук, И. Ю. Сольская. - М. : Учеб.-метод. центр по образованию на ж.-д. транспорте, 2012. -288 с.

11. Курсаков В. В. Проблемы развития системы государственного контроля в условиях финансового кризиса / В. В. Курсаков, И. Ю. Сольская // Современные технологии. Системный анализ. Моделирование. - 2012. - № 3 (35). - С. 201-204.

12. Развитие российского общества: социально-экономические и правовые исследования / О. В. Батурина [и др.] ; под ред. М. А. Винокурова, А. П. Киреенко, С. В. Чупрова. М. : Наука, 2014. - 622 с.

13. Чистякова О. В. Инновационные направления развития предпринимательства в Байкальском регионе / О. В. Чистякова. - Иркутск : Изд-во БГУЭП, 2012. - 206 с.

14. Шуплецов А. Ф. Естественные монополии в переходной экономике: особенности регулирования / А. Ф. Шуплецов. - Иркутск : Изд-во БГУЭП, 2006. - 127 с.

\section{References}

1. Dal V. I. Tolkovyi slovar zhivogo velikorusskogo yazyka [The Explanatory Dictionary of the Living Great Russian Language]. Moscow, GIS Publ., 1955.

2. Azriliyan A. N. (ed.). Bol'shoi ekonomicheskii slovar' [Great Business Dictionary]. Moscow, Fund «Legal Culture» Publ., 1994. 528 p.

3. Burovtsev V. V. Ekonomicheskaya otsenka litsenzionnogo bar'era pri for-mirovanii konkurentnoi sredy na rynke gruzovykh zheleznodorozhnykh perevozok. Avtoref. Kand. Diss. [Economic assessment of license barrier in developing competitive environment on the market of rail fright traffic. Cand. Diss. Thesis]. Novosibirsk, 2006. 190 p.

4. Chanyshev A. N. Kurs lektsii po drevnei filosofii [Course of Lectures on Ancient Philosophy]. Moscow, Vysshaya shkola Publ., 1981. 374 p.

5. Aristotle; Asmus V. F. (ed.). Sochineniya [Treatises]. Moscow, Mysl’ Publ., 1978-1983.

6. Dushenko K. V. Universal'nyi tsitatnik politika i zhurnalista: 6000 tsitat o politike, pravosudii i zhurnalistike [A universal quotation book for politicians and journalists: 6000 quotations on policy, justice and journalism]. $4^{\text {th }}$ ed. Moscow, Eksmo Publ., 2006. 508 p.

7. Onikov L. A., Shishlin N. V. (eds). Kratkii politicheskii slovar' [A Concise Political Dictionary]. $5^{\text {th }}$ ed. Moscow, Politizdat Publ., 1989. 623 p.

8. Cherkovets V. (ed.). Vsemirnaya istoriya ekonomicheskoi mysli [The world history of economic thought]. Moscow, Mysl' Publ., 1987. Vol. 1. 606 p.

9. Burovtsev V. V. Upravlenie administrativnym bar'erom $v$ usloviyakh transformatsii ekonomicheskoi sistemy [Management of administrative barrier in terms of transforming economic system]. Novosibirsk, Siberian Transport University Publ., 2011. 159 p.

10. Burovtsev V. V., Mitsuk I. V., Solskaya I. Yu. Gosudarstvennoe regulirovanie zheleznodorozhnogo transporta $v$ period reformirovaniya [State regulation of railway transport in the

\section{Baikal Research Journal}


period of reforming]. Moscow, The Training Center for Education on Railway Transport Publ., 2012. $288 \mathrm{p}$.

11. Kursakov V. V., Solskaya I. Yu. Problems of developing system of governmental control in terms of financial crisis. Sovremennye tekhnologii. Sistemnyi analiz. Modelirovanie = Modern Technologies. System Analysis. Modeling, 2012, no. 3 (35), pp. 201-204. (In Russian).

12. Baturina O. V. et al.; Vinokurov M. A., Kireyenko A. P., Chuprov S. V. (eds). Razvitie Rossiiskogo obshchestva: sotsial'no-ekonomicheskie i pravovye issledovaniya [Development of Russian society: socio-economic and legal research]. Moscow, Nauka Publ., 2014. 622 p.

13. Chistyakova $\mathrm{O}$. V. Innovatsionnye napravleniya razvitiya predprinimatel'stva $v$ Baikal'skom regione [Innovative directions of business development in Baikal region]. Irkutsk, Baikal State University of Economics and Law Publ., 2012. 206 p.

14. Shupletsov A. F. Estestvennye monopolii v perekhodnoi ekonomike: osobennosti regulirovaniya [Natural monopolies in transitional economy: features of regulation. Irkutsk, Baikal State University of Economics and Law Publ., 2006. 127 p.

\section{Информация об авторе}

Буровцев Владилир Викторович - кандидат экономических наук, доцент, кафедра государственного и муниципального управления, Сибирский государственный университет путей сообщения, 630049, г. Новосибирск, ул. Д. Ковальчук, 191, e-mail: BurovtsevVV@mail.ru.

\section{Author}

Vladimir V. Burovtsev - PhD in Economics, Associate Professor, Chair of Public and Municipal Administration, Siberian Railway Engineering University, 191 D. Kovalchuk St., 630049, Novosibirsk, Russian Federation; e-mail: BurovtsevVV@mail.ru.

\section{Библиографическое описание статьи}

Буровцев В. В. Исторические и философские аспекты взаимосвязи предпринимательской среды и государства / В. В. Буровцев / Baikal Research Journal. — 2016. — T. 7, № 2. — DOI : 10.17150/2411-6262.2016.7(2).16.

\section{Reference to article}

Burovtsev V. V. Historical and philosophical aspects of interrelation of business environment and government. Baikal Research Journal, 2016, vol. 7, no. 2. DOI: 10.17150/24116262.2016.7(2).16. (In Russian).

\section{Baikal Research Journal}

